\title{
Exercise-induced Pulmonary Vasoconstriction during Combined Blockade of Nitric Oxide Synthase and Beta Adrenergic Receptors
}

\author{
Douglas W. Kane, Thomas Tesauro, Tomonobu Koizumi, Rishi Gupta, and John H. Newman \\ Center for Lung Research, Vanderbilt University School of Medicine, Nashville, Tennessee 37232
}

\begin{abstract}
We studied the effects of inhibition of nitric oxide (NO) (endothelium-derived relaxation factor) synthase in combination with alpha and beta adrenergic receptor blockade on pulmonary vascular tone during exercise. In paired studies, we exercised sheep on a treadmill at a speed of $4 \mathrm{mph}$, and measured blood flow and pressures across the pulmonary circulation with and without inhibition of $\mathrm{NO}$ synthase ( $\mathbf{N} \omega$-nitro-L-arginine 20 $\mathrm{mg} / \mathrm{kg}$ intravenous [i.v.]), alpha receptor blockade (phentolamine $5 \mathrm{mg}$ i.v.), beta receptor blockade (propranolol $1 \mathrm{mg}$ i.v.), and combined alpha and beta receptor blockade. Activation of both types of adrenergic receptors occurs with exercise, and because increased release in NO is hypothesized to occur during exercise, these studies were designed to determine the magnitude of effect and interactions of these competing dilator and constrictor influences. We found that inhibition of NO synthase raised pulmonary vascular resistance (PVR) at rest and that, although a reduction in PVR occurred with exercise from this new baseline, vasoconstriction persisted. Combined beta blockade and NO synthase inhibition unmasked unopposed alpha vasoconstriction; PVR rose at rest and continued to rise with exercise; and mean pulmonary arterial pressures approached very high levels, $43.8 \pm 4.4 \mathrm{cmH}_{2} \mathrm{O}$. Using a distal wedged pulmonary artery catheter technique, most of the vasoconstriction was found to be in vessels upstream from small pulmonary veins. During exercise in sheep there appears to be a high degree of alpha and beta adrenergic-mediated tone in the pulmonary circulation. Endogenous production of NO actively dilates pulmonary vessels at rest and opposes potent alpha-mediated pulmonary vasoconstriction during exercise. (J. Clin. Invest. 1994. 93:677-683.) Key words: exercise • pulmonary circulation • nitric oxide $\bullet$ vasoconstriction $\bullet$ adrenergic
\end{abstract}

\section{Introduction}

The purpose of these experiments was to study the interaction of endogenous nitric oxide (NO) ${ }^{1}$ and adrenergic activation on pressure and blood flow in the lung in exercising sheep.

Address correspondence to John H. Newman, M.D., B1308 Vanderbilt Medical Center North, Nashville, TN 37232. 1993.

Received for publication 3 June 1993 and in revised form 11 August

1. Abbreviations used in this paper: $\mathrm{CO}$, cardiac output; EDRF, endothelium-derived relaxation factor; NLA, N $\omega$-nitro-L-arginine; NO, nitric oxide; $\mathrm{Pla}$, left atrial pressure; $\mathrm{Ppa}$, pulmonary artery pressure; PVR, pulmonary vascular resistance.

J. Clin. Invest.

(c) The American Society for Clinical Investigation, Inc.

0021-9738/94/02/0677/07 \$2.00

Volume 93, February 1994, 677-683
Endogenous NO has been shown to be important in modulating resting pulmonary vascular tone (1-4), but has not been studied during exercise. Because endothelial-dependent vessel relaxation is enhanced by increases in flow and pressure (5-8), one might expect NO to be released during moderate exercise, where cardiac output increases by two- to fourfold. Resting vascular tone is also modulated by basal adrenergic output (912 ). We recently observed that alpha and beta adrenergic activation occurs during exercise in sheep and that pulmonary vascular resistance (PVR) was most affected by alpha constriction when beta receptors were blocked (13). In addition to direct vasodilation, endothelium-derived relaxation factor (EDRF) may modulate vascular tone in part by interaction with the sympathetic nervous system, by reducing sympathetic nerve outflow (14-17), or by reducing synaptic norepinephrine efflux (18). The constrictor effect of alpha adrenoreceptor agonists is potentiated by removal of the endothelium or by EDRF inhibition $(19,20)$. NO opposes alpha-1-induced vasoconstriction, and endothelial alpha-2 activation may in fact stimulate EDRF production or release $(15,16)$.

PVR decreases by $\sim 30 \%$ during constant rate, high intensity exercise in sheep $(21,22)$. Most of the decrease in PVR occurs within 20-40 s of onset of exercise and is not affected by adrenergic blockade (13). This adrenergic-independent decrease may be due to passive vasodilation $(13,23)$. A second, slower decrease in PVR is modulated by adrenergic receptors and is blocked during the unopposed alpha-mediated constriction that occurs during beta blockade (13).

Based on these observations, we hypothesized that EDRF blockade would modify and reduce the dilating effects of exercise on the pulmonary vascular bed, and that the combination of EDRF and beta adrenergic blockade would remove a potent vasodilating response to exercise and reveal an antagonistic vasoconstrictive effect of concurrent alpha receptor activation. We pursued this hypothesis in sheep in paired studies during rest and exercise with single and combined alpha and beta receptor blockade and EDRF inhibition.

\section{Methods}

Surgical preparation. We prepared 13 sheep $(25-30 \mathrm{~kg})$ for chronic hemodynamic measurements as described previously (21-23). Under general anesthesia, the left atrium and main pulmonary artery were cannulated with silastic catheters through a left thoracotomy. An ultrasonic flow probe (Transonic Systems, Inc., Ithaca, NY) was placed around the proximal main pulmonary artery for continuous measurement of cardiac output (CO). An introducer (model 8; Cordis Laboratories Inc., Miami, FL) was inserted into the internal jugular vein through a right neck incision, and a silastic catheter was placed into the carotid artery. All catheters were flushed with heparinized saline and were sewn to the skin. Sheep were allowed to recover in pens for 4-7 d after surgery with free access to water and feed.

Exercise apparatus and training. Animals were fitted with a padded leather collar that was attached at a comfortable level to side posts built into a standard treadmill (Quinton Instruments, Seattle, WA). Train- 
ing consisted of repeated trotting on the treadmill for 5-8 d until each animal was familiar with the procedure and was able to trot comfortably at $4 \mathrm{mph}$ for 5-10 $\mathrm{min}(13,21)$.

Physiologic measurements. Pressures were recorded at rest and during exercise, using pressure transducers (Hewlett-Packard Co., Andover, MA), signal conditioners (Validyne Engineering Corp., Northridge, CA), and recorder (Astro-Med, Inc., West Warwick, RI). $\mathrm{CO}$ was measured continuously by the implanted ultrasonic flow probe and was displayed with the pressure data. $\mathrm{CO}$ was also measured intermittently by thermodilution. Guided by pressure deflections, a No. 7 Swan-Ganz catheter was advanced into the pulmonary artery through the introducer. $\mathrm{CO}$ was taken as the mean of four to six samples using 10-ml boluses of iced saline (Edwards Laboratories, Santa Ana, CA). It was not possible to obtain reproducible thermodilution $\mathrm{COs}$ while the animals were running. To correlate ultrasonic flow with thermodilution measurements, we administered isoproterenol (Elkins-Sinn, Cherry Hill, NJ), $10 \mathrm{mg} / 250 \mathrm{ml} 0.9 \%$ saline i.v. to each sheep at rest, via an infusion pump at rates that produced a range of $\mathrm{CO}$ similar to those seen during exercise. Flow probe and thermodilution values were recorded simultaneously, and a regression plot and equation were constructed for each animal. The derived formula was then used to correct each flow probe value during exercise to the thermodilution standard $(13,22)$.

Arterial blood $\mathrm{pH}, \mathrm{PCO}_{2}$, and $\mathrm{PO}_{2}$ were measured on a blood gas analyzer (Corning Medical and Scientific, Medfield, MA). PVR was calculated by the equation: ( $\mathrm{Ppa}-\mathrm{Pla}$ )/CO, where $\mathrm{Ppa}$ and $\mathrm{Pla}$ are mean pulmonary artery and left atrial pressures in $\mathrm{cm} \mathrm{H}_{2} \mathrm{O}$. $\mathrm{CO}$ was expressed in liters per minute.

Drug dosing and administration. N $\omega$-nitro-L-arginine (NLA) (Sigma Chemical Co., St. Louis, MO), a potent stereospecific competitive inhibitor of NO synthase, was used for EDRF inhibition $(2,24)$. NLA was dissolved with $0.1 \mathrm{~N} \mathrm{HCl}$, was titrated to a $\mathrm{pH}$ of $7.00 \pm 0.5$, and was brought to a final volume of $30 \mathrm{ml}$ in sterile saline. NLA ( 20 $\mathrm{mg} / \mathrm{kg}$ ) was administered via the pulmonary artery catheter $(1,2)$. Maximal effect was observed by $20 \mathrm{~min}$, and Ppa remained elevated for up to $4 \mathrm{~h}$. In several sheep, the specificity of NLA for NO synthase was shown by reversal of the hemodynamic effect of NLA within 4-8 min after the administration of $150-200 \mathrm{mg} / \mathrm{kg}$ i.v. of L-arginine, $10 \%$ solution (25).

Propranolol (Ayerst, New York) was used for beta receptor blockade (13). The dose was based on the amount required in preliminary experiments to reverse a $30 \%$ increase in heart rate and to return Ppa to baseline during an infusion with isoproterenol. We found that the minimum effective dose that was both well tolerated and allowed a maximal effect was $1 \mathrm{mg}$ i.v. We gave propranolol by bolus via the pulmonary artery catheter. We observed no hemodynamic effects of propranolol at rest or beyond $30 \mathrm{~min}$ after dosing. The reported $t_{1 / 2}$ for the L-isomer is $40 \mathrm{~min}$ (26). Phentolamine (Ciba Pharmaceuticals, Summit, $\mathrm{NJ}$ ) was used for alpha blockade (13). The dose was based on the amount required in preliminary experiments to return pulmonary and systemic blood pressure to baseline after preconstriction to $30 \%$ above baseline with a continuous infusion of norepinephrine $(4 \mathrm{mg}$ in $50 \mathrm{ml}$ saline) (Winthrop Laboratories, New York). We did not observe exercise intolerance with phentolamine. The effective dose was a 5-mg i.v. bolus via the pulmonary artery catheter. No hemodynamic effects were observed at rest or exercise beyond $20 \mathrm{~min}$ from the time of injection. $t_{1 / 2}$ for phentolamine is reported to be $19.5 \mathrm{~min}$ in humans (27). For control studies, $5.0 \mathrm{ml}$ of diluent $(0.9 \% \mathrm{NaCl})$ was injected into the pulmonary artery catheter. The dosing schedule was the same as we have reported previously (13).

Exercise protocols. In paired studies, eight sheep underwent the following exercise experiments after the following separate interventions: ( $a$ ) placebo control (diluent), (b) EDRF inhibition, $(c)$ alpha adrenergic blockade with and without EDRF inhibition, $(d)$ beta adrenergic blockade with and without EDRF inhibition, and $(e)$ combined alpha and beta blockade with and without EDRF inhibition. Data with alpha and beta blockade but not with EDRF inhibition or combined adrenergic blockade and EDRF inhibition was reported pre- viously as part of a group of 17 animals (13). Two to three interventions were done on each experimental day. We varied the order of study. Because of the prolonged effect of NLA, only one study employing NLA was permitted on any day.

In five additional sheep we followed the same exercise protocol with the combination of beta blockade and EDRF inhibition, and we measured microwedge pressure via a No. 7 Swan-Ganz catheter as described previously (22). This technique allows partitioning of the pressure, drop into two segments, one upstream from small veins having diameters approximately equal to the catheter and the other downstream from these small veins $(22,28)$. The diameter of the catheter is $2.3 \mathrm{~mm}$. PVR was calculated as PVR $=(\mathrm{Ppa}-\mathrm{Pla}) / \mathrm{CO}, \mathrm{PVR}$ upstream as (Ppa - Pwedge)/CO, and PVR downstream as (Pwedge $\mathrm{Pla}) / \mathrm{CO}$.

The following protocol was employed for controls and every intervention. Resting values of all hemodynamic variables were obtained for 15-30 min. Drugs were given by bolus via the pulmonary artery catheter. Measurements were made continuously before and after drug administration. After infusion of NLA, 20 min were required to reach steady state. After infusion of phentolamine and/or propranolol, sheep were allowed to stand quietly for 3-5 min to achieve a new steady state before exercise. The treadmill was then started at a preset speed of 4 $\mathrm{mph}$ and $0 \%$ grade, and sheep trotted for a minimum of $240 \mathrm{~s}$. Carotid artery blood was withdrawn for gas tension and $\mathrm{pH}$ measurement at rest before and after drug administration, and after $4 \mathrm{~min}$ of exercise. Mean values for $\mathrm{BP}, \mathrm{Ppa}, \mathrm{Pla}$, and $\mathrm{CO}$ were transcribed at 20 -s intervals and were stored on a computer spreadsheet.

Statistical tests. Data are displayed as means \pm SEM. We used Quattro Pro (Borland Co., Scotts Valley, CA) for collation and descriptive statistics and Number Cruncher Statistical System (Kaysville, UT) for comparisons. Data were analyzed by one- and two-way ANOVA, using repeated measures for two-way comparisons. Comparisons of individual points between groups were made by Duncan's multiple range test. Wilcoxon signed rank test was used for within group comparisons for a single variable. Significant differences were accepted at $P<0.05$.

\section{Results}

\section{Hemodynamic changes during exercise}

Control runs. Ppa nearly doubled during the first 20 s of exercise, followed by a gradual reduction to a new steady state at about $180 \mathrm{~s}$ (Table I). Pla changes followed a similar pattern and timing. $\mathrm{CO}$ rose abruptly at the onset of exercise and doubled within the first $60 \mathrm{~s}$. The range of $\mathrm{CO}$ during 20-240 s of exercise was $7.5 \pm 0.3-8.6 \pm 0.3 \mathrm{liter} / \mathrm{m}$. Mean systemic blood pressure increased modestly during the first $20 \mathrm{~s}$ of exercise and continued to rise slowly to a peak of $102.5 \pm 3.3 \mathrm{mmHg}$ at $240 \mathrm{~s}$. The greatest rate of PVR reduction occurred during the first 20 $s$ (Table I, and Figs. 1 and 2), with a drop from $2.7 \pm 0.3$ to $2.2 \pm 0.3$ Wood units, followed by a gradual decline to a nadir of $1.7 \pm 0.2$ Wood units by the end of the run $(240 \mathrm{~s})$. Arterial blood $\mathrm{pH}, \mathrm{PO}_{2}$, and $\mathrm{PCO}_{2}$ were unchanged during exercise (Table II).

Alpha blockade and exercise. Ppa and Pla rose with the onset of exercise, and then fell to a steady state numerically lower than that of control runs (Table I). The increase in CO was similar to that of controls. Phentolamine did not significantly change the increase in mean systemic blood pressure during exercise. The reduction in PVR was no different than control during any phase of the run (Fig. 1). Arterial blood pH, $\mathrm{PO}_{2}$, and $\mathrm{PCO}_{2}$ were not altered by phentolamine during exercise ( Table II).

Beta blockade during exercise. Ppa rose significantly with exercise, reaching a peak at $80 \mathrm{~s}$ as opposed to $20 \mathrm{~s}$ in controls 
Table I. Hemodynamic Effects of Alpha and Beta Blockade and EDRF Inhibition at Rest and Exercise in Sheep $(n=8)$

\begin{tabular}{|c|c|c|c|c|}
\hline & \multicolumn{2}{|c|}{ Rest } & \multicolumn{2}{|c|}{ Exercise } \\
\hline & Pre-drug & Post-drug & $20 \mathrm{~s}$ & $240 \mathrm{~s}$ \\
\hline \multicolumn{5}{|l|}{ Ppa } \\
\hline Control & $15.3 \pm 0.6$ & $15.3 \pm 0.6$ & $25.6 \pm 1.6^{*}$ & $21.6 \pm 1.1^{*}$ \\
\hline Phentolamine & $15.5 \pm 0.4$ & $14.3 \pm 0.5^{\ddagger}$ & $19.9 \pm 1.5^{*}$ & $17.0 \pm 1.0^{*}$ \\
\hline Propranolol & $14.8 \pm 0.9$ & $16.5 \pm 1.1^{\ddagger}$ & $28.9 \pm 1.4^{*}$ & $30.1 \pm 1.9^{*}$ \\
\hline Prop plus phen & $15.0 \pm 0.5$ & $14.4 \pm 0.8$ & $21.6 \pm 1.8^{*}$ & $20.6 \pm 1.2^{*}$ \\
\hline NLA & $14.9 \pm 0.5$ & $20.9 \pm 1.7^{\ddagger}$ & $31.8 \pm 2.8^{*}$ & $31.6 \pm 2.3^{*}$ \\
\hline NLA plus phen & $15.0 \pm 0.5$ & $19.3 \pm 1.6^{\ddagger}$ & $27.6 \pm 2.8^{*}$ & $25.3 \pm 2.1^{*}$ \\
\hline NLA plus prop & $14.4 \pm 0.7$ & $19.5 \pm 1.9^{\ddagger}$ & $39.6 \pm 3.2^{*}$ & $43.4 \pm 4.4^{*}$ \\
\hline \multicolumn{5}{|l|}{ NLA plus prop } \\
\hline plus phen & $15.0 \pm 0.6$ & $19.5 \pm 1.6$ & $32.5 \pm 3.1$ & $28.9 \pm 3.4$ \\
\hline \multicolumn{5}{|l|}{ PLA } \\
\hline Control & $3.9 \pm 0.4$ & $3.9 \pm 0.4$ & $9.4 \pm 1.0^{*}$ & $7.3 \pm 1.5$ \\
\hline Phentolamine & $4.1 \pm 0.4$ & $1.6 \pm 0.8^{\ddagger}$ & $3.5 \pm 1.0$ & $3.3 \pm 1.3$ \\
\hline Propranolol & $4.0 \pm 0.6$ & $5.4 \pm 0.7^{\ddagger}$ & $16.4 \pm 1.0^{*}$ & $13.5 \pm 1.6^{*}$ \\
\hline Phen plus prop & $4.4 \pm 0.6$ & $3.2 \pm 0.5^{\ddagger}$ & $8.5 \pm 1.2^{*}$ & $7.5 \pm 0.9^{*}$ \\
\hline NLA & $3.7 \pm 0.5$ & $6.6 \pm 0.8^{\ddagger}$ & $9.1 \pm 1.1^{*}$ & $8.1 \pm 1.5^{*}$ \\
\hline NLA plus phen & $3.4 \pm 0.7$ & $3.0 \pm 1.1$ & $2.0 \pm 1.3$ & $1.3 \pm 1.0$ \\
\hline NLA plus prop & $3.9 \pm 0.5$ & $5.0 \pm 0.8^{\ddagger}$ & $13.9 \pm 1.8^{*}$ & $14.0 \pm 1.7^{*}$ \\
\hline \multicolumn{5}{|l|}{ NLA plus phen } \\
\hline plus prop & $3.6 \pm 0.7$ & $0.9 \pm 1.0^{\ddagger}$ & $7.6 \pm 1.0^{*}$ & $6.4 \pm 1.1^{*}$ \\
\hline \multicolumn{5}{|l|}{$\mathrm{CO}$} \\
\hline Control & $4.4 \pm 0.3$ & $4.4 \pm 0.3$ & $7.5 \pm 0.3^{*}$ & $8.6 \pm 0.4^{*}$ \\
\hline Phentolamine & $4.6 \pm 0.4$ & $5.2 \pm 0.4^{\ddagger}$ & $8.3 \pm 0.5^{*}$ & $9.7 \pm 0.5^{*}$ \\
\hline Propanolol & $4.8 \pm 0.3$ & $4.6 \pm 0.4^{\ddagger}$ & $6.4 \pm 0.4^{*}$ & $7.8 \pm 0.5^{*}$ \\
\hline Phen plus prop & $4.6 \pm 0.4$ & $4.6 \pm 0.4$ & $6.7 \pm 0.4^{*}$ & $8.4 \pm 0.9^{*}$ \\
\hline NLA & $4.2 \pm 0.4$ & $3.5 \pm 0.3^{\ddagger}$ & $5.9 \pm 0.3^{*}$ & $7.4 \pm 0.8^{*}$ \\
\hline NLA plus phen & $4.1 \pm 0.4$ & $3.8 \pm 0.3$ & $6.1 \pm 0.4^{*}$ & $8.2 \pm 1.0^{*}$ \\
\hline NLA plus prop & $4.1 \pm 0.4$ & $3.4 \pm 0.3^{\ddagger}$ & $5.5 \pm 0.5^{*}$ & $6.8 \pm 1.0^{*}$ \\
\hline \multicolumn{5}{|l|}{ NLA plus phen } \\
\hline plus prop & $4.1 \pm 0.4$ & $3.7 \pm 0.4^{\ddagger}$ & $5.7 \pm 0.5^{*}$ & $7.1 \pm 0.9^{*}$ \\
\hline \multicolumn{5}{|l|}{ BP } \\
\hline Control & $78.0 \pm 3.3$ & $78.0 \pm 3.3$ & $95.0 \pm 2.7^{*}$ & $102.5 \pm 3.3^{*}$ \\
\hline Phentolamine & $82.3 \pm 2.4$ & $76.0 \pm 1.2^{\ddagger}$ & $88.2 \pm 4.0^{*}$ & $92.3 \pm 2.4$ \\
\hline Propranolol & $81.3 \pm 3.2$ & $81.0 \pm 3.0$ & $87.8 \pm 5.9$ & $97.7 \pm 5.3^{*}$ \\
\hline Phen plus prop & $78.8 \pm 4.6$ & $75.3 \pm 4.3$ & $80.0 \pm 2.5$ & $92.5 \pm 6.3^{*}$ \\
\hline NLA & $78.3 \pm 2.7$ & $95.8 \pm 6.6^{\ddagger}$ & $104.2 \pm 5.6$ & $110.8 \pm 5.5^{*}$ \\
\hline NLA plus phen & $78.3 \pm 2.7$ & $93.8 \pm 5.7^{\ddagger}$ & $95.7 \pm 6.0$ & $105.0 \pm 5.9^{*}$ \\
\hline NLA plus prop & $79.7 \pm 2.8$ & $92.2 \pm 6.7^{\ddagger}$ & $108.8 \pm 6.2^{*}$ & $117.2 \pm 4.8^{*}$ \\
\hline \multicolumn{5}{|l|}{ NLA plus phen } \\
\hline plus prop & $84.2 \pm 3.4$ & $91.2 \pm 6.0$ & $100.3 \pm 6.1^{*}$ & $110.0 \pm 5.8^{*}$ \\
\hline \multicolumn{5}{|l|}{ PVR } \\
\hline Control & $2.7 \pm 0.3$ & $2.7 \pm 0.3$ & $2.2 \pm 0.3^{*}$ & $1.7 \pm 0.2^{*}$ \\
\hline Phentolamine & $2.6 \pm 0.2$ & $2.5 \pm 0.2$ & $2.0 \pm 0.3^{*}$ & $1.5 \pm 0.2^{*}$ \\
\hline Propranolol & $2.3 \pm 0.3$ & $2.5 \pm 0.4^{\ddagger}$ & $2.0 \pm 0.3^{*}$ & $2.2 \pm 0.3$ \\
\hline Phen plus prop & $2.4 \pm 0.3$ & $2.6 \pm 0.3$ & $2.0 \pm 0.3^{*}$ & $1.7 \pm 0.3^{*}$ \\
\hline NLA & $2.7 \pm 0.2$ & $4.0 \pm 0.4^{\ddagger}$ & $4.0 \pm 0.4$ & $3.6 \pm 0.4$ \\
\hline NLA plus phen & $3.0 \pm 0.3$ & $4.4 \pm 0.5^{\ddagger}$ & $4.4 \pm 0.6$ & $3.2 \pm 0.5^{*}$ \\
\hline NLA plus prop & $2.7 \pm 0.3$ & $4.4 \pm 0.7^{\ddagger}$ & $4.9 \pm 0.9$ & $4.9 \pm 1.0$ \\
\hline \multicolumn{5}{|l|}{ NLA plus phen } \\
\hline plus prop & $2.9 \pm 0.3$ & $5.4 \pm 0.9^{\ddagger}$ & $4.7 \pm 0.7$ & $3.6 \pm 0.7^{*}$ \\
\hline
\end{tabular}

Mean Ppa and Pla were measured in centimeters of $\mathrm{H}_{2} \mathrm{O} \pm$ SEM. CO was measured in liters per minute. PVR, Ppa - Pla/CO; Phen, phentolamine; Prop, propranolol. * Different from rest post-drug. ${ }^{\ddagger}$ Different from rest pre-drug, $P<0.05$.

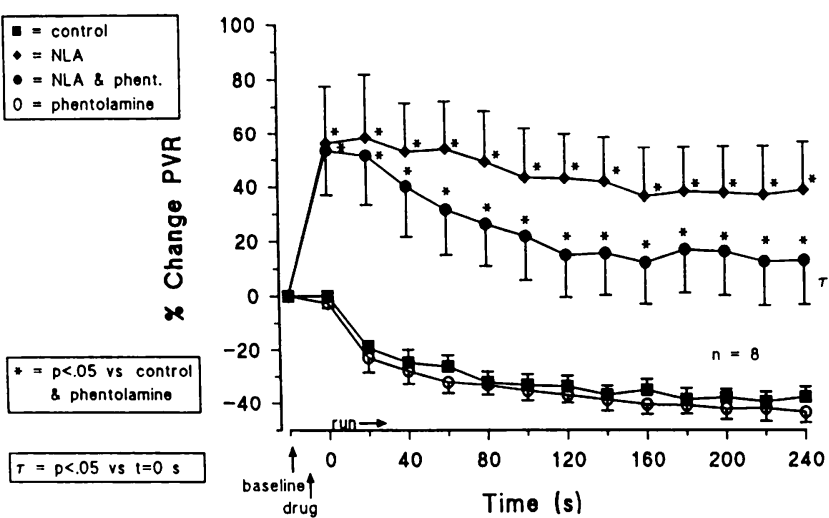

Figure 1. PVR at rest, after drug infusion, and during constant rate exercise at $4 \mathrm{mph}$ in eight sheep with and without phentolamine (phent.) or NLA. Phentolamine did not affect PVR. NLA raised PVR at rest and during exercise. The rise in PVR at rest with NLA was not reversed by phentolamine, but PVR during exercise trended lower during treatment with NLA plus phentolamine.

(Table I). Peak Ppa was higher than in control runs at $40 \mathrm{~s}$ and was sustained throughout the run. Pla was higher than in control runs throughout the exercise period. $\mathrm{CO}$ increased but never reached levels of control runs. The increase in mean systemic blood pressure was similar to that of controls. The reduction in PVR during the first $20 \mathrm{~s}(-20.0 \pm 8.1 \%)$ was similar in magnitude to that of alpha blockade $(-20.3 \pm 5.5 \%)$ and control runs $(-19.2 \pm 2.6 \%)$ (Figs. 1 and 3 ). PVR actually increased slightly between 20 and $40 \mathrm{~s}$ of exercise and did not decrease thereafter (Figs. 2 and 3). Arterial blood pH, $\mathrm{PO}_{2}$, and $\mathrm{PCO}_{2}$ did not change with beta blockade during exercise (Table II).

Combined alpha and beta blockade during exercise. The combination of propranolol and phentolamine resulted in a hemodynamic response during exercise similar to that of control runs and to that previously reported (Table I, Fig. 4) (13).

NO synthesis blockade during exercise. Ppa rose to a higher level than in control runs, and the $\mathrm{CO}$ response was lower ( $\mathrm{Ta}$ ble I). PVR was higher than in control runs throughout the

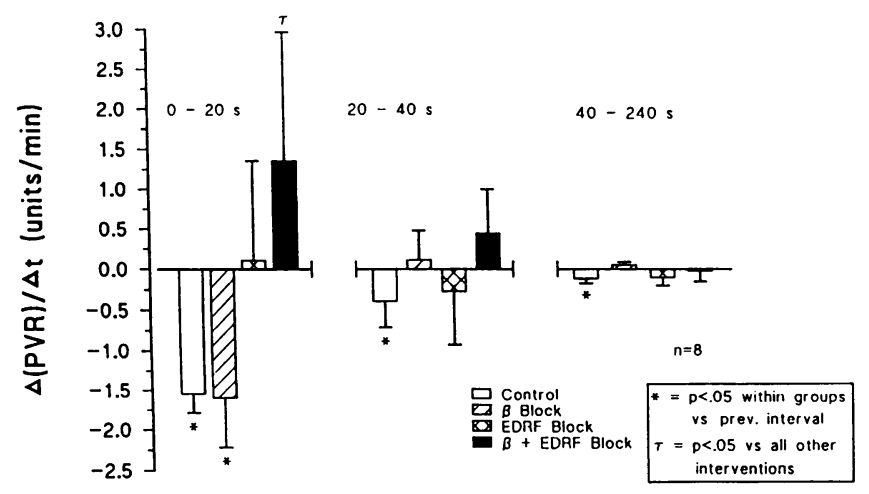

Figure 2. The change in PVR as a function of time during exercise at $4 \mathrm{mph}$ in eight sheep with and without propranolol or NLA. In controls, $0-20 \mathrm{~s}$ represents the early reduction thought to be due to recruitment of microvessels; $20-40 \mathrm{~s}$ is transition; 40-240 s depicts a slower small reduction in PVR towards steady state (Control). PVR decreased as expected with beta blockade but actually rose during combined beta blockade and NO synthase inhibition. 
Table II. Effect of Alpha and Beta Blockade and EDRF Inhibition at Rest and Exercise on pH, $\mathrm{PaO}_{2}$, and $\mathrm{PaCO}_{2}$ in $\mathrm{Sheep}_{(n=8)}$

\begin{tabular}{|c|c|c|c|c|c|c|}
\hline & \multicolumn{3}{|c|}{ Rest } & \multicolumn{3}{|c|}{ Exercise } \\
\hline & pH & $\mathrm{PaCO}_{2}$ & $\mathrm{PaO}_{2}$ & $\mathrm{pH}$ & $\mathrm{PaCO}_{2}$ & $\mathrm{PaO}_{2}$ \\
\hline Control & $7.52 \pm 0.02$ & $31.84 \pm 1.42$ & $81.54 \pm 3.80$ & $7.51 \pm 0.01$ & $31.04 \pm 1.12$ & $80.39 \pm 4.21$ \\
\hline NLA & $7.52 \pm 0.02$ & $32.71 \pm 1.95$ & $77.61 \pm 4.36$ & $7.52 \pm 0.02$ & $31.89 \pm 1.22$ & $74.63 \pm 2.30$ \\
\hline NLA plus alpha & $7.53 \pm 0.01$ & $32.07 \pm 1.37$ & $78.24 \pm 2.16$ & $7.52 \pm 0.01$ & $30.57 \pm 1.37$ & $77.14 \pm 3.48$ \\
\hline NLA plus beta & $7.59 \pm 0.02$ & $28.22 \pm 2.32$ & $73.84 \pm 4.48$ & $7.54 \pm 0.01$ & $30.51 \pm 1.47$ & $64.06 \pm 4.45^{*}$ \\
\hline NLA plus alpha plus beta & $7.50 \pm 0.02$ & $33.17 \pm 1.03$ & $81.36 \pm 5.59$ & $7.52 \pm 0.03$ & $31.24 \pm 1.45$ & $78.77 \pm 6.14$ \\
\hline
\end{tabular}

* Different from rest, $P<0.05$.

exercise period (Fig. 3). PVR did not decrease during the first $20 \mathrm{~s}$ of exercise in contrast to single and combined adrenoreceptor blockade and control runs (Figs. 2 and 4 ). The reduction in PVR between 40 and $240 \mathrm{~s}$ was similar to that of controls. No changes in arterial blood $\mathrm{pH}, \mathrm{PaO}_{2}$, and $\mathrm{PCO}_{2}$ occurred at rest or during exercise after administration of NLA ( Table II).

Alpha blockade plus NO synthase inhibition during exercise. Ppa increased at the onset of exercise, followed by a small but insignificant reduction by 240 s (Table I, Fig. 1). Pla decreased throughout the exercise period. The $\mathrm{CO}$ was similar to control, and mean BP rose slightly. PVR did not decline during the first $20 \mathrm{~s}$, but decreased between 20 and $100 \mathrm{~s}$ of trotting to a net decrease of about $40 \%$ from the peak (Fig. 1, Table I). Arterial blood $\mathrm{pH}, \mathrm{PaO}_{2}$, and $\mathrm{PCO}_{2}$ did not change during exercise with NLA and alpha blockade (Table II). Alpha adrenoreceptor blockade plus NLA resulted in a reduction in the exercise increase in Ppa, but not to control levels, a delayed reduction in PVR, and a PVR that remained higher than control runs (Fig. 1).

Beta blockade plus NO synthase inhibition during exercise. The increase in Ppa and Pla in the first 20 s of exercise was greater than that of all other interventions ( $\mathrm{Ppa}$ [19.5 \pm 1.9 $\left.39.6 \pm 3.2 \mathrm{cmH}_{2} \mathrm{O}\right]$, and Pla [5.0 $\left.\pm 0.8-13.9 \pm 1.8 \mathrm{cmH}_{2} \mathrm{O}\right]$ ) ( Table I, Fig. 3). Ppa continued to rise to a peak of $44.8 \pm 4.27$ $\mathrm{cmH}_{2} \mathrm{O}$ at $100 \mathrm{~s}$, while Pla remained stable. $\mathrm{CO}$ was lower, and

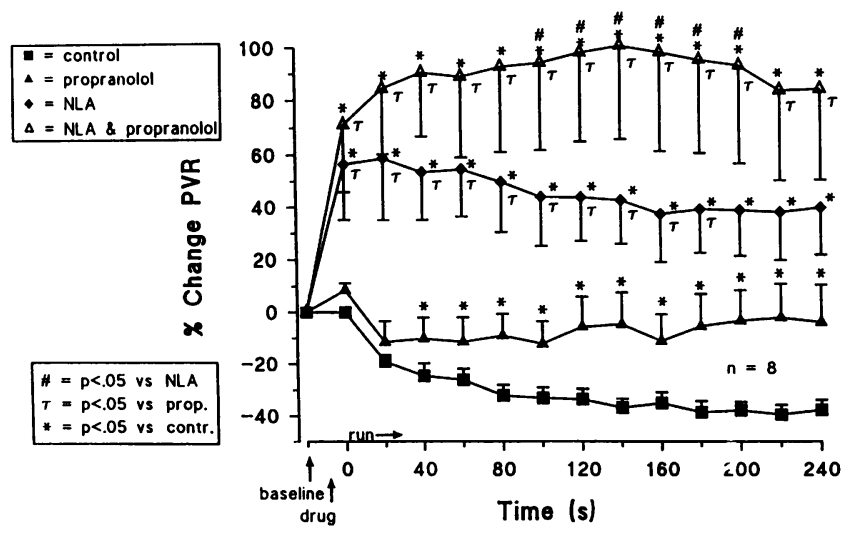

Figure 3. PVR at rest, after drug infusion, and during constant rate exercise at $4 \mathrm{mph}$ in eight sheep with and without propranolol (prop.) or NLA. NLA and NLA plus propranolol raised PVR dramatically at rest, whereas there was a small effect with propranolol alone. PVR rose during exercise with NLA plus propranolol and trended down with NLA alone and propranolol alone. Vasoconstriction persisted in all three treated groups. the BP was greater than in controls. Most notable was the increase in PVR with exercise (Figs. 2 and 3). PVR increased from $71 \pm 21 \%$ to $84 \pm 24 \%$ during the early phase $(0-20 \mathrm{~s})$ and continued to rise until $140 \mathrm{~s}$, when PVR was $28.8 \%$ above resting postdrug values and $136.7 \%$ above controls (Fig. 3). Arterial $\mathrm{PO}_{2}$ decreased from $73.8 \pm 4.5$ at rest to $64.1 \pm 4.5$ $\mathrm{mmHg}$ during exercise.

Microwedge data during NO synthase inhibition or the combination of EDRF inhibition and beta blockade are shown in Figs. 5 and 6. Most of the pressure difference was between the main pulmonary artery catheter and the microwedge. Thus, the vasoconstriction at rest and exercise is largely in prealveolar vessels.

Combined adrenergic blockade plus NO synthase inhibition during exercise. The pulmonary pressure response was similar to that with NLA alone, and the change in Pla was numerically similar to that of control runs. $\mathrm{CO}$ changes were less than in control but were not different from other NLA trials (Fig. 4). Mean BP was not significantly affected. Unlike propranolol plus NLA, the PVR dropped during the first 20 s from $82 \pm 21 \%$ to $59 \pm 17 \%$ above baseline $(22.3 \%)$, which is similar to the $19 \pm 3 \%$ drop in control runs (Fig. 4). PVR continued to decrease between 40 and $240 \mathrm{~s}$. Arterial blood $\mathrm{pH}, \mathrm{PaO}_{2}$, and $\mathrm{PCO}_{2}$ were not affected ( Table II). In summary, adding alpha blockade to combined beta adrenergic and EDRF inhibition restored the early and late reduction in PVR during exercise.

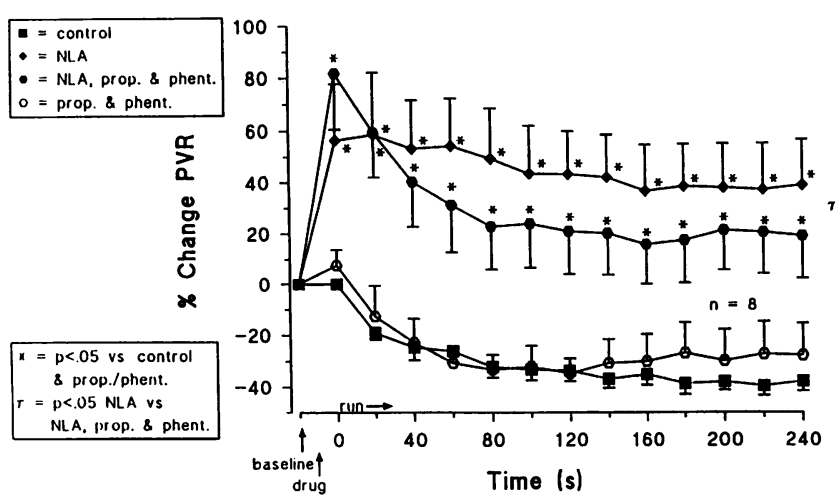

Figure 4. PVR at rest, after drug infusion, and during constant rate exercise at $4 \mathrm{mph}$ in eight sheep with either alpha and beta blockade alone (propranolol plus phentolamine), NLA alone, or combined NLA plus adrenergic blockade. Runs during alpha plus beta blockade were no different than controls. The effects of alpha plus beta blockade during EDRF inhibition were similar to those of alpha blockade during EDRF inhibition (Fig. 1). 

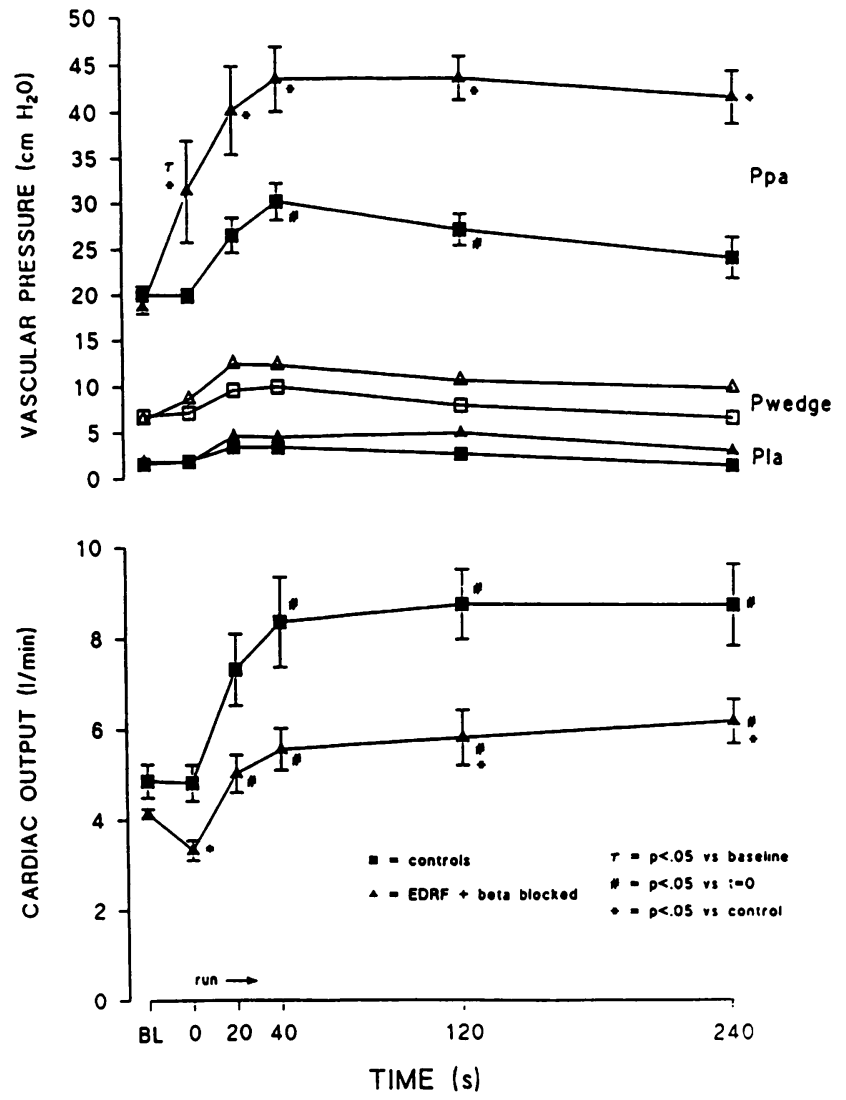

Figure 5. Pulmonary hemodynamics at rest and during exercise at 4 $\mathrm{mph}$ in five additional sheep with and without NLA (EDRF blocked) plus propranolol (beta blocked). Pwedge is the pressure measured by the distal-wedge technique $(22,28)$. Most of the pressure change in the main pulmonary artery is in upstream, precapillary vessels. The higher pressures during EDRF blockade runs occurred at a lower $\mathrm{CO}$, denoting true vasoconstriction. Plas were minimally changed.

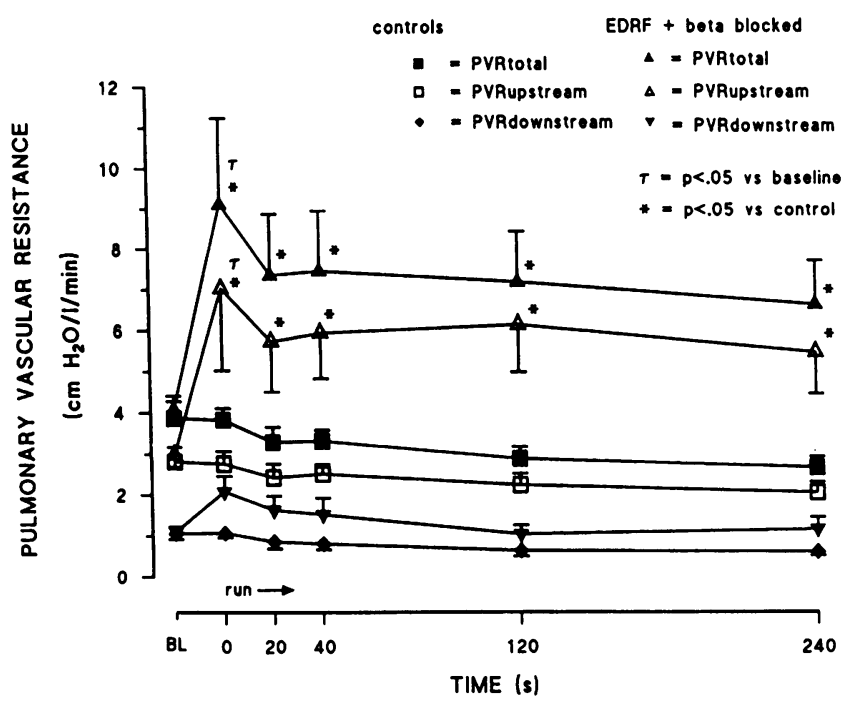

Figure 6. Total PVR (Ppa-Pla)/CO, upstream PVR (Ppa-Pwedge)/ $\mathrm{CO}$, and downstream PVR (Pwedge-Pla)/CO in five additional sheep at rest and at $4 \mathrm{mph}$ with and without propranolol (beta blocked) and NLA (EDRF blocked). Almost all of the vasoconstriction at rest and exercise was in upstream (precapillary) vessels. There was a small increase $(P=\mathrm{NS})$ in downstream resistance.
PVR was higher than control levels, indicating a continued effect of EDRF inhibition.

Effects of adrenergic receptor blockade on hemodynamics at rest. The effects of propranolol and phentolamine alone and in combination at rest are shown in Table I and Fig. 4. The data are similar to those reported previously (13). Phentolamine caused small but significant reductions in Ppa, Pla, and BP, and a small increase in CO. PVR was unchanged. Propranolol caused small but significant increases in Ppa and Pla, and a slight reduction in $\mathrm{CO}$. The increase in Ppa exceeded the increase in Pla, suggesting pulmonary vasoconstriction. Combined adrenoreceptor blockade caused a small decrease in Pla, but no other hemodynamic changes. Arterial $\mathrm{pH}, \mathrm{PaCO}_{2}$, and $\mathrm{PaO}_{2}$ were not affected by any combination of adrenoreceptor blockade at rest (Table II).

Effects of NO synthase inhibition and adrenoreceptor blockade at rest. NLA alone resulted in significant increases in Ppa, Pla, BP, and PVR, and a reduction in CO (Table I, Fig. 3). PVR rose by $56 \pm 21 \%$. Ppa increased more than Pla at a lower $\mathrm{CO}$, denoting pulmonary vasoconstriction.

NLA plus phentolamine increased Ppa, PVR, and BP but less than with NLA alone. Pla and $\mathrm{CO}$ were unchanged. The increase in PVR with NLA plus phentolamine was not different from that with NLA alone (Fig. 2, Table I).

NLA plus propranolol caused significant increases in Ppa, $\mathrm{Pla}, \mathrm{BP}$, and PVR, and a fall in CO. PVR rose by $71 \pm 25 \%$ (Fig. 3 , Table I), which was significantly higher than the PVR of all the other treatments except for that of NLA alone.

NLA plus combined adrenoreceptor blockade caused significant increases in Ppa, BP, PVR, and a decrease in $\mathrm{CO}$ and $\mathrm{Pla}$ (Table I). PVR rose by $82 \pm 21 \%$, which was similar to that of NLA alone (Fig. 1). No changes in arterial pH, $\mathrm{PaCO}_{2}$, or $\mathrm{PaO}_{2}$ occurred as a consequence of drug administration in any group at rest (Table II).

\section{Discussion}

The purpose of this study was to discover the interaction of endogenous NO and the sympathetic nervous system on hemodynamics of the lung during exercise. We have recently shown that both alpha and beta adrenergic receptors are activated in the pulmonary circulation during exercise and that beta blockade results in modest vasoconstriction that persists during exercise (13). We hypothesized that inhibition of NO synthase would result in vasoconstriction during exercise, partly because NO release is enhanced during shear stress of cultured endothelial cells $(5,7)$, and increased vascular wall shear stress should exist in the lung during exercise. In addition, because NO has effects that are antagonistic to norepinephrine and because endogenous NO may modulate noradrenergic synapses (14-18), we hypothesized that combined inhibition of vasodilating effects of beta receptors and of NO synthase would reveal the net vasoconstricting power of sympathetic output on the pulmonary circulation.

We found that beta blockade or NO synthase inhibition alone resulted in moderate increases in PVR during exercise, but that the combination resulted in intense, sustained vasoconstriction associated with mean Ppa between 40 and 50 $\mathrm{cmH}_{2} \mathrm{O}$. In addition, combined blockade masked the usual decrease in PVR that occurs during the first 20-40 s of exercise, thought to be due to dilation of vessels of low critical opening pressure $(13,21)$. The microwedge data show that most of the 
effects of beta blockade and EDRF inhibition (and thus, unopposed alpha receptor activation) are upstream from small veins. Thus, the increase in PVR (Figs. 4 and 5 ) measured by the pressure in the catheter in the main pulmonary artery masks the recruitment and reduction in PVR occurring downstream of the site of vasoconstriction.

The effects of beta blockade and EDRF inhibition were evident at rest, where mild vasoconstriction was observed, but the combination at rest was not additive, presumably because of the low level of sympathetic tone at rest. During exercise, the evidence points to massive activation of alpha and beta receptors and of NO release, the balance of which favors net mild vasodilation. Of interest, combined beta and alpha blockade results in a hemodynamic response similar to that of unblocked exercise as reported previously (13). Thus, these competing effects are balanced equally at rest and during exercise, when both types of receptors are activated.

This study was not designed to comprehensively evaluate the role of endogenous NO in the pulmonary circulation during exercise. Such a study will require measurements after infusion of a substrate for NO such as L-arginine, reversal of the effects of NLA with exogenous L-arginine, measurement of the effects of inhaled exogenous NO on pulmonary hemodynamics at rest and during exercise, and measurement of the effects of inhaled NO and L-arginine on the preconstricted pulmonary vascular bed. But, the basic effects of endogenous NO in sheep at rest and during exercise are clear. First, basal release of endogenous NO contributes to the low PVR seen at rest in sheep. This appears to be true in some other species (1-3), but has not been tested to our knowledge in humans. Second, the vasoconstriction that occurs with inhibition of NO synthase at rest largely persists during exercise. Third, most of the pulmonary vasoconstriction resulting from inhibition of NO synthase is in the bed upstream from small veins, which includes the pulmonary arteries and extra-alveolar vessels. Fourth, NO synthase inhibition does not fully prevent the decrease in PVR during exercise that occurs from the new postinhibition baseline. Mechanical or flow-related effects that induce vasodilation, probably via recruitment of microvessels, are unimpaired. Thus, in the normal animal, endogenous NO modulates resting and exercise pulmonary vascular tone equally. The effect of NO is not significantly enhanced during the increased blood flow of strenuous exercise.

It is not known whether or not disorders of the release and effect of NO are important in clinical diseases of the pulmonary circulation (29-31). Massive NO release may be partly responsible for the systemic hypotension that occurs with endotoxemia (32-34), but endotoxemia is usually associated with pulmonary hypertension, not hypotension. Humans with adult respiratory distress syndrome have recently been shown to respond to exogenous NO with pulmonary vasodilation and improvement in gas exchange (35). Thus, the human pulmonary circulation should be capable of responding to NO, but it is not clear that failure of NO effects, synthesis, or transduction are responsible for any disease associated with vasoconstriction. The function of NO synthase in disorders associated with pulmonary hypertension, such as sepsis and neurogenic pulmonary edema, might be studied in this context. The level of mean Ppa attained during exercise in sheep during combined blockade of $\mathrm{NO}$ synthase was $43.4 \pm 4.4 \mathrm{~cm} \mathrm{H}_{2} \mathrm{O}$. This is a level that could potentially impair right ventricular function, and, if transmitted to the capillary bed, could cause a marked increase in filtration.

In summary, we have made a novel observation, that potent pulmonary vasoconstriction can be elicited during exercise in normal animals by coexistent inhibition of NO synthase and beta adrenergic blockade. This effect is apparently due to sympathetic activation of constrictor alpha adrenergic receptors. It is possible that abnormalities of NO release or effects in context of increased sympathetic tone may contribute to disorders of the pulmonary circulation associated with pulmonary hypertension.

\section{Acknowledgments}

This study was supported by National Institutes of Health grants HL45107, HL-07123, and HL-19153, and the Saint Thomas Foundation.

\section{References}

1. Perrella, M. A., E. S. Edell, M. J. Krowka, D. A. Cortese, and J. C. Burnett, Jr. 1992. Endothelium-derived relaxing factor in pulmonary and renal circulations during hypoxia. Am. J. Physiol. 263:R45-R50.

2. Fineman, J. R., M. A. Heymann, and S. J. Soifer. 1991. N $\omega$-nitro-L-arginine attenuates endothelium-dependent pulmonary vasodilation in lambs. Am. J. Physiol. 260:H1299-H1306.

3. Archer, S. L., K. Rist, D. P. Nelson, E. G. DeMaster, N. Cowan, and E. K. Weir. 1990. Comparison of the hemodynamic effects of nitric oxide and endothelium-dependent vasodilators in intact lungs. J. Appl. Physiol. 68:735-747.

4. Brashers, V. L., M. J. Peach, and C. E. Rose, Jr. 1988. Augmentation of hypoxic pulmonary vasoconstriction in the isolated perfused rat lung by in vitro antagonists of endothelium-dependent relaxation. J. Clin. Invest. 82:1495-1502.

5. Holtz, J., U. Forstermann, U. Pohl, M. Giesler, and E. Bassenge. 1984. Flow-dependent, endothelium-mediated dilation of epicardial coronary arteries in conscious dogs: effects of cyclooxygenase inhibition. J. Cardiovasc. Pharmacol. 6:1161-1167.

6. Palmer, R. M. J., A. G. Ferrige, and S. Moncada. 1987. Nitric oxide release accounts for the biological activity of endothelium-relaxing factor. Nature (Lond.). 327:524-526.

7. Buga, G. M., M. E. Gold, J. M. Fukuto, and L. J. Ignarro. 1991. Shear stress-induced release of nitric oxide from endothelial cells grown on beads. $\mathrm{Hy}$ pertension (Dallas). 17:187-193.

8. Davies, P. F. 1989. How do vascular endothelial cells respond to flow? News Physiol. Sci. 4:22-25.

9. Long, W. A., and D. L. Brown. 1990. Central neural regulation of the pulmonary circulation. In The Pulmonary Circulation: Normal and Abnormal. A. P. Fishman, editor. University of Pennsylvania Press, Philadelphia. 131-149.

10. Hyman, A. L., and P. L. Kadowitz. 1986. Enhancement of $\alpha$-and $\beta$-adrenoreceptor responses by elevations in vascular tone in pulmonary circulation. Am. J. Physiol. 19:H1109-1116.

11. Murray, P. A., R. F. Lodato, and J. R. Michael. 1986. Neural antagonists modulate pulmonary vascular pressure-flow plots in conscious dogs. J. Appl. Physiol. 60:1900-1907.

12. Hyman, A. L., H. L. Lipton, C. W. Dempsy, C. J. Fontana, D. E. Richardson, R. W. Rieck, and P. L. Kadowitz. 1989. Autonomic control of the pulmonary circulation. In Pulmonary Vascular Physiology and Pathophysiology. Vol. 38: Lung Biology in Health and Disease. E. K. Weir and J. T. Reeves, editors. Marcel Dekker Inc., New York. 291-324.

13. Kane, D. W., T. A. Tesauro, and J. H. Newman. 1993. Adrenergic modulation of pulmonary hemodynamics during strenuous exercise in sheep. Am. Rev. Respir. Dis. 147:1233-1238.

14. Sakuma, I., H. Togashi, M. Yoshioka, H. Saito, M. Yanagida, M. Tamura T. Kobayashi, H. Yasuda, S. S. Gross, and R. Levi. 1992. Ng-methyl-L-arginine, an inhibitor of L-arginine-derived nitric oxide synthesis, stimulates renal sympathetic nerve activity in vivo. Circ. Res. 70:607-611.

15. Miller, V. M. 1991. Interactions between neural and endothelial mechanisms in control of vascular tone. News Physiol. Sci. 6:60-63.

16. Ohyanagi, M., K. Nishigaki, and J. E. Faber. 1991. Interaction between $\alpha$-adrenoceptors (ARs) and endothelial-derived relaxant factor (EDRF) in the microcirculation. Blood Vessels. 28:327.

17. Greenberg, S. S., F. P. J. Diecke, K. Peevy, and T. P. Tanaka. 1990. Release of norepinephrine from adrenergic nerve endings of blood vessels is modulated by endothelium-derived relaxing factor. Am. J. Hypertens. 3:211-218.

18. Greenberg, S. S., K. Peevy, and T. P. Tanaka. 1991. Endothelium-derived 
and intraneuronal nitric oxide-dependent inhibition of norepinephrine efflux from sympathetic nerves by bradykinin. Am. J. Hypertens. 4:464-467.

19. Vane, J. R., E. E. Anggard, and R. M. Botting. 1990. Regulatory functions of the vascular endothelium. N. Engl. J. Med. 323:27-36.

20. Furchgott, R. F. 1983. Role of endothelium in responses of vascular smooth muscle. Circ. Res. 53:557-573.

21. Newman, J. H., B. J. Butka, R. C. Parker, and R. Roselli. 1988. Effect of progressive exercise on lung fluid balance in sheep. J. Appl. Physiol. 64:21252131.

22. Newman, J. H., C. P. Cochran, R. J. Roselli, R. E. Parker, and L. S. King. 1993. Pressure and flow changes in the pulmonary circulation in exercising sheep: evidence for elevated microvascular pressure. Am. Rev. Respir. Dis. 147:921927.

23. Reeves, J. T., J. A. Dempsey, and R. F. Grover. 1989. Pulmonary circulation during exercise. In Pulmonary Vascular Physiology and Pathophysiology. E. K. Weir and J. T. Reeves, editors. Marcel Dekker Inc., New York. 107-133.

24. Rees, D. D., R. M. Palmer, H. F. Hodson, and S. Moncada. 1989. A specific inhibitor of nitric oxide formation from $\mathrm{L}$-arginine attenuates endothelium-dependent relaxation. Br. J. Pharmacol. 96:418-424.

25. Koizumi, T., R. Gupta, and J. H. Newman. 1993. Inhibition of EDRF results in marked vasoconstriction of upstream pulmonary vessels during exercise in sheep. Am. Rev. Respir. Dis. 149:226a. (Abstr.)

26. Drayer, D. E. 1987. Lipophilicity, hydrophilicity and the central nervous system: side effects of beta blockers. Pharmacotherapy. 7:87-91.

27. Hoffman, B. B., and R. J. Lef kowitz. 1989. Catecholamines and sympathomimetic drugs. In The Pharmacological Basis of Therapeutics. 6th ed. L. S. Goodman and A. Gilman, editors. MacMillan, New York. 187-200.
28. Parker, R. E., and K. L. Brigham. 1987. Effects of endotoxemia on pulmonary vascular resistances in unanesthetized sheep. J. Appl. Physiol. 63:10581062.

29. Dinh-Xuan, A. T., T. W. Higenbottam, C. A. Clelland, J. Pepke-Zaba, G. Cremona, A. Y. Butt, S. R. Large, F. C. Wells, and J. Wallwork. 1991. Impairment of endothelium-dependent pulmonary-artery relaxation in chronic obstructive lung disease. $N$. Engl. J. Med. 324:1539-1547.

30. Wylam, M. E., R. W. Samsel, J. G. Umans, R. W. Mitchell, A. R. Leff, and P. T. Schumacker. 1990. Endotoxin in vivo impairs endothelium-dependent relaxation of canine arteries in vitro. Am. Rev. Respir. Dis. 142:1263-1267.

31. Frostell, C., M. D. Fratacci, J. C. Wain, R. Jones, and W. M. Zapol. 1991 Inhaled nitric oxide. A selective pulmonary vasodilator reversing hypoxic pulmonary vasoconstriction. Circulation. 83:2038-2047.

32. Kilbourn, R. G., A. Jubran, S. S. Gross, O. W. Griffith, R. Levi, J. Adams, and R. F. Lodato. 1990. Reversal of endotoxin-mediated shock by $\mathrm{N}^{\mathrm{G}}$-methyl-Larginine, an inhibitor of nitric oxide synthesis. Biochem. Biophys. Res. Commun. 172:1132-1138.

33. Flemming, I., G. Julou-Schaeffer, G. A. Gray, J. R. Parrat, and J. C. Stoclet. 1991. Evidence that an L-arginine/nitric oxide dependent elevation of tissue cyclic GMP content is involved in depression of vascular reactivity by endotoxin. Br. J. Pharmacol. 103:1947-1952.

34. Nava, E., R. M. J. Palmer, and S. Moncada. 1991. Inhibition of nitric oxide synthesis in septic shock: how much is beneficial? Lancet. 338:1555-1557.

35. Rossaint, R., K. J. Falke, F. Lopez, K. Slama, U. Pison, and W. M. Zapol. 1993. Inhaled nitric oxide for the adult respiratory distress syndrome. $N$. Engl. J. Med. 328:399-405 